\title{
A Gestalt-Terapia na Fronteira: Alteridade Reconhecimento como Cuidado
}

\author{
Gestalt Therapy at the Boundary: Otherness and Recognition \\ as Care
}

\section{La Gestalt Terapia en la Frontera: Otredad y Reconocimiento como Cuidado}

\author{
Monica Botelho Alvim* \\ Universidade Federal do Rio de Janeiro - UFRJ, Rio de Janeiro, Rio de Janeiro, Brasil
}

\begin{abstract}
RESUMO
O artigo propõe uma discussão sobre os desafios da clínica da GestaltTerapia no trabalho com populações em situação de invisibilidade social abordando, a partir da sua noção de fronteira de contato, os temas da alteridade e do reconhecimento como constitutivos de uma ação clínica de cuidado neste contexto. A partir de diálogos interdisciplinares, em especial com perspectivas do campo da filosofia, o trabalho propõe uma breve análise crítica da situação contemporânea, apontando para as relações entre fronteiras de direitos, invisibilidade social e existencial, propondo uma ação clínica fundada na ética da alteridade e da transformação que promova um trabalho clínico que aconteça na fronteira, no encontro com populações invisibilizadas e buscando dar a ver o que os afeta sem se mostrar. Apresenta os contornos gerais de um trabalho clínico com jovens de favelas, colocando em questão os direitos e o lugar do Estado para que o reconhecimento possa ser plenamente exercido e sua dimensão de potencializar a agência se realize. Conclui por considerar o trabalho com a alteridade e o reconhecimento como forma de cuidado que possibilita resgatar a capacidade de agência, a partir de uma ação clínica ampliada para a situação-favela em suas dimensões micro e macro políticas.
\end{abstract}

Palavras-chave: invisibilidade social, clínica ampliada, direitos humanos, arte, corpo.

\begin{abstract}
The article proposes a discussion about the challenges of the Gestalt Therapy clinic in working with socially invisible populations, approaching, from its notion of contact boundary, the themes of alterity and recognition as constitutive of a clinical care action in this context. From interdisciplinary dialogues, especially with perspectives from the field of philosophy, the paper proposes a brief critical analysis of the contemporary situation, pointing to the relations between boundaries of rights, social and existential invisibility, and then proposing a clinical action based on an ethics of otherness and transformation that promotes a clinical work that happens in the frontier, in the encounter with those invisible populations and trying to show what affects them without showing itself. It presents the general
\end{abstract}


outlines of a clinical work with youths who live in slums, calling into question the rights and place of the state so that recognition can be fully exercised and its dimension of empowering the agency realized. It concludes by considering the work with otherness and recognition as a form of care that allows rescuing the agency capacity from an expanded clinical action for the slum situation in its micro and macro political dimensions.

Keywords: social invisibility, expanded clinic, human rights, art, body.

\begin{abstract}
RESUMEN
El artículo propone una discusión sobre los desafíos de la Terapia Gestalt al trabajar con poblaciones socialmente invisibles, abordando, desde su noción de frontera de contacto, los temas de alteridad y reconocimiento como constitutivos de una acción de atención clínica en ese contexto. Desde diálogos interdisciplinarios, especialmente con perspectivas del campo de la filosofía, el documento propone un breve análisis crítico de la situación contemporánea, señalando las relaciones entre los límites de los derechos, la invisibilidad social y existencial, proponiendo una acción clínica basada en la ética de la alteridad y de la transformación que promueva un trabajo clínico que ocurra en la frontera, en el encuentro con poblaciones invisibles y tratando de mostrar lo que les afecta sin mostrarse. El trabajo presenta los contornos generales del trabajo clínico con jóvenes de barrios marginales, cuestionando los derechos y el lugar del estado para que el reconocimiento pueda ejercerse plenamente y su dimensión de potencializar la capacidad de agencia sea realizada. Concluye considerando el trabajo con la alteridad y lo reconocimiento como una forma de atención que permite rescatar la capacidad de agencia por medio de una acción clínica extendida a la situación de las favelas en sus dimensiones micro y macro políticas.
\end{abstract}

Palabras clave: invisibilidad social, clínica ampliada, derechos humanos, arte, cuerpo.

Assumo como ponto de partida para essa reflexão sobre o cuidado em Gestalt-Terapia a noção de fronteira. Laura Perls (2012) deu ao único livro de sua inteira autoria o título "Living at the Boundary" (Vivendo na Fronteira), atribuindo ao viver na fronteira um estatuto central para suas discussões sobre a Gestalt-Terapia.

A fronteira de contato é concebida pela Gestalt-Terapia como o tempo-lugar do encontro: encontrar a novidade, o outro, o diferente, o estranho a mim e permanecendo nesta fronteira - de contato viver a experiência do estranhamento, do excitamento e do crescimento por meio da criação.

Pensar em fronteira dessa forma, torce o que comumente se pensa sobre as fronteiras, concebidas como aquelas que dividem e separam territórios, nações, espaços, povos: em Berlim, outrora, foi construído um muro que dividia ocidente e oriente; na China, também se construiu uma muralha para impedir a entrada de nômades; Donald Trump pretendeu construir um muro para impedir que latino-americanos entrassem no território norte-americano; na região da Faixa de Gaza há o muro da Cisjordânia que separa judeus e palestinos. 
Há fronteiras mais abstratas, que separam e demarcam divisões de outras ordens: a fronteira entre o pensar e o fazer; entre a criança e o adulto; entre mim e o outro; entre o pobre e o rico, o homem e a mulher, o negro e o branco, o homossexual e o heterossexual. Há ainda fronteiras religiosas, fronteiras de direitos.

Oceanos e mares funcionam como fronteiras que unem e separam ao mesmo tempo. Pensar no oceano-mar como um espaço de ninguém, onde se pode flutuar e se deixar levar até desembocar em terra firme, foi por muito tempo para mim uma imagem poética que me trazia uma sensação de aventura e liberdade, um tipo de liberdade que não significa seguir a própria vontade, mas que tem muita ressonância com a proposta gestáltica de um modo espontâneo de estar no mundo. Em um tipo de interação que não é nem atividade pura e nem passividade pura. O trecho de uma música do Paulinho da Viola que diz "Não sou eu quem me navega quem me navega é o mar" (Paulinho da Viola, 1993) traduz muito bem isto que estou tentando dizer.

Hoje, entretanto, quando penso nessa imagem do mar, não sinto mais aquela sensação boa de aventura. Ela deu lugar à angústia diante das imagens que a televisão mostra de botes e boias apinhadas de gente. Isto mesmo, gente. Na "aventura" de sobreviver à fome, fugir da guerra, de várias formas de opressão e de encontrar um lugar minimamente seguro e digno para viver, eles se põem nos barcos para atravessar o mar. E lembro-me agora de outro trecho da música do Paulinho da Viola que fala do aviso do pai para os perigos do mar: "Olha, o mar não tem cabelos que a gente possa agarrar." (Paulinho da Viola, 1993). O risco (muito grande) de morte que essas pessoas assumem ao atravessarem o mar de forma tão precária, é a última esperança de travessia da fronteira entre a vida sem vida e uma vida minimamente viva. Na maioria das vezes, todavia, elas não chegam lá. Ou, quando chegam, são mandadas de volta, esbarram nas fronteiras feitas de arames farpados. Ou ainda, desterradas, permanecem nos campos de refugiados.

Cercas e muros, diferentes do mar, são fronteiras não-naturais, criadas para conter movimentos de travessia. Para barrar um espaço do suposto perigo do outro lado. Dividindo seguro e inseguro. Nativo e estrangeiro. Autorizado e não-autorizado. Gloria Anzaldúa (1999) fala da fronteira Estados Unidos-México - onde Trump queria construir um muro - como uma ferida aberta no primeiro mundo que sangra com a fricção do terceiro mundo. Alguns lugares da Europa sangram hoje com a fricção de outros povos. Nas zonas fronteiriças, as feridas sangram mais e mais. Os campos de refugiados, as ruas dos países mais ao sul, à beira do oceano, mesmo os mais ao norte, são borderlands, como denomina Anzaldúa as regiões que ficam na fronteira, aquelas habitadas pela massa de proscritos. O sul e o norte ali se misturam e as tensões fazem sangrar todos. A terrível 
experiência do desterro encontra nessa situação uma versão radical. O desterro que os leva à condição de nômades, apátridas.

Assim como os muros que não permitem ver o outro lado, as fronteiras que são elas mesmas invisíveis, podem invisibilizar territórios e pessoas.

\section{Fronteiras de direitos, invisibilidade social e existencial}

As fronteiras demarcadas por exclusão e negação de direitos básicos como educação, saúde, segurança, trabalho digno são, de certo modo, invisíveis. Assim, mesmo pensando em direitos humanos, que em tese seriam de todos os humanos, há fronteiras entre eles. Alguns têm direito ao direito; outros não. Essas fronteiras, a princípio invisíveis, são instauradas por pessoas que ascenderam ao poder com a promessa de representarem o outro, mas que não pensam senão na preservação do próprio poder. Ricoeur (2006) nos lembra de que quando a pessoa natural nomeia um representante - pessoa artificial - cede a ele o direito de governar ela mesma. Criar um representante é promover um tipo de transferência que leva a sociedade a um ordenamento do múltiplo ao uno. A pessoa una por excelência é o Estado. Para Leibniz, o objeto de direito "É tudo aquilo que importa a outrem que the façamos e que está em nosso poder." (Leibniz como citado em Ricoeur, 2006, p. 185). Mas não há direitos para todos os humanos quando não há compromisso do Estado com essa premissa básica do direito de orientar-se pelo que importa a outrem que lhe façamos.

Essas fronteiras inicialmente abstratas que separam direitos, passam a ser fronteiras geográficas, geopolíticas, que distanciam e invisibilizam as pessoas sem direitos. Aqueles aos quais são negados direitos básicos vivem nas periferias, nas zonas mais distantes, nas margens, como as favelas cariocas. Privados de formas dignas de vida que os permitam sentir que pertencem a um lugar, performam a tragédia cotidiana da luta por sobrevivência em meio à guerra entre 0 Estado e o tráfico. A eles estão destinadas as zonas periféricas da cidade que poderíamos, com Anzaldúa (1999), denominar borderlands ou zonas de fronteira. Boaventura de Sousa Santos (1994) nos convida a fazer uma deslocação radical, saindo do centro e indo para as margens, para que possamos ver microscopicamente o que excluímos para nos manter no centro. Mas como propôs DidiHuberman (2010), a experiência de ver de verdade implica ser olhado pelo que vemos. Invisibilizar o outro pode ser pensado, assim, como um tipo de violência que funciona como um gesto de tapar os próprios olhos, retirando o outro do meu campo de visão, para que o que eu veria nele, não possa também me olhar e me inquietar. Um gesto que visa a aplacar a angústia do encontro com sua diferença. 
E podemos nesse ponto de nossa reflexão, ampliar o tema da invisibilização para dimensões menos geográficas e adentrar o terreno da invisibilidade como não-direito à existência igualitária. Aos invisibilizados é negada, desta maneira, a relação de alteridade, o direito de ser um outro para mim, um outro eu que pode igualmente se ver como Um e, de seu lugar, me ver como um Outro.

Toda forma de relação pautada por relações de dominação embute um modo colonizador do outro e da alteridade constitutiva de relações igualitárias. Como discute Enrique Dussel em sua crítica à Modernidade, a Europa, buscando naquele período afirmar-se como o centro da história, só conseguiu isso quando invisibilizou o nãoeuropeu (seu outro) pela violência da dominação e colonização. $O$ outro não foi "des-coberto" como outro, mas foi en-coberto como o si-mesmo que a Europa já era desde sempre. E foi negado a ele o lugar de alteridade (Dussel, 1993).

Colonizar o outro implica apagar suas formas singulares de ser e estar para submetê-lo a um tipo de ordenamento externo que, supostamente, irá civilizá-lo. Deste modo, esse outro não é compreendido e experienciado como um outro eu, que comunga comigo de uma dimensão comum, mas como um outro totalmente outro e que - compreendido como selvagem, falhado, marginal, monstro, pervertido - deve: ou ser aniquilado; ou ser colonizado, recriado à minha imagem e semelhança. A relação com o outro deixa de ser igualitária, no sentido de que ser um e outro são lugares que revezamos, implicando que eu possa ver o outro a partir da minha referência de um, mas possa também admitir que o outro tenha a legitimidade de ocupar o lugar de um e me situar no de outro.

O tema do reconhecimento envolve em seu cerne a relação com o outro, o poder de agir e o direito, como aquele que transforma a liberdade abstrata em oportunidade real (Ricoeur, 2006) e permite agir. A liberdade para agir, segundo o autor, implica tudo o que alguém é capaz de realizar e implica a ausência de entraves impostos ao indivíduo pelo outro ou pelo Estado.

Quando pensamos em direitos, pensamos em sujeitos que pertencem igualitariamente, que são parte de uma comunidade e têm reconhecimento social. São eu e outro, e estabelecem entre si relações de alteridade.

Temos vivido, nos tempos recentes, experiências radicais de recusa da diferença e do direito à diferença. Como num déjà vu, vemos forças fascistas que avançam com suas armas para ocupar o território social, político, existencial, sem deixar espaço para a diferença, para o exercício da alteridade que movimenta a criação. 0 fascismo apoia-se em um sentimento nacionalista de patriotismo que afirma colocar a pátria no lugar de uno, mas que, em realidade, quer garantir a manutenção do poder nas mãos de um só, o soberano e seu grupo mais próximo. As tentativas de colonizar o pensamento e o 
sentimento têm como alvo as instituições democráticas de garantia de direitos, de saúde, de educação e de cultura. Aprofundando as fronteiras de raça, fronteiras de gênero, fronteiras de classe, de credo, buscam empurrar para fora e para as margens, para as borderlands, para a zona de proscritos, a diversidade daqueles que não cedem às práticas de normalização. Eliminando os ditos marginais com suas políticas genocidas.

As forças fascistas atuais apostam na divisão e nas fronteiras como aquelas que separam. Fomentam um estado de guerra e polarizações entre pessoas e grupos. Querem mais armas que possam deixar o dito cidadão de bem seguro e legitimado para aniquilar o dito marginal. E quem são os marginais? O termo marginal que literalmente significa estar na margem e não no centro, transformouse em sinônimo de criminalidade.

As zonas da margem ou borderlands são, segundo Anzaldua (1999), locais de encontro de excluídos e diferentes. São espaços de diversidade de todo tipo. De povos que falam diferentes línguas, sotaques, que vêm de diferentes lugares, pessoas que vivem a experiência radical da alteridade, mais ainda, que vivem a experiência do desterro e que podem encontrar nas relações atuais, novas formas de relação, de com-partilhamento e de solidariedade. E que nos referimos aqui como nômades contemporâneos.

Nas zonas do centro habitamos nós, os sedentários contemporâneos. Em nossas casas de tijolos, cercadas de muros, às vezes de cercas elétricas, ou em nossos apartamentos entre paredes que separam cômodos, criamos pequenos territórios onde nos mantemos enraizados em nossa terra, permanecendo em segurança dentro de nossas fronteiras, mais ou menos protegidos dos perigos da cidade. Nossos consultórios representam igualmente pequenos "territóriosnações", onde nos encontramos com diferentes mundos, com seres que por vezes falam línguas estrangeiras à nossa, que têm sotaques diferentes, mas que, em algum grau, são parte de um centro citadino no qual pertencemos. E que são reconhecidos em sua maioria como sujeitos de direitos, com os quais podemos estabelecer relações de alteridade.

No entanto, entre nós - sedentários habitantes do centro - e eles nômades que circulam nas borderlands - há fronteiras muito demarcadas. E pensamos nas possibilidades e impossibilidades de um trabalho clínico nesse contexto.

\section{A clínica gestáltica e seus movimentos no contemporâneo: uma reflexão necessária}

Muitas vezes referimo-nos à Gestalt-Terapia como uma proposta revolucionária. Uma das revoluções que fez, foi essa torção no modo 
de compreender a fronteira à qual me referi antes. Em lugar de separar, a fronteira é compreendida como espaço-tempo de encontrar com a diferença e a oportunidade de criação e expansão. Fundada, portanto, em uma "ética da alteridade e ética da transformação" (Alvim \& Castro, 2015, p. 45). Para os autores, estas duas dimensões éticas da clínica são intimamente relacionadas. A ética da alteridade "implica ter como ponto de partida o outro como sujeito e nós como sujeito para o outro" (Alvim \& Castro, 2015, p. 45) considerando uma dimensão comum e uma dimensão de diferença e estranhamento que movimente a criação e que seja transformadora da situação.

Meu convite aqui para nós, gestalt-terapeutas, é fazermos uma reflexão acerca do caráter revolucionário - e, portanto, ético-político - da nossa clínica. Cabe pensar o que temos feito e o que podemos fazer para nos mantermos alinhados com a proposta de uma clínica que permita viver na fronteira e movimentar a transformação.

Laura Perls (2012) compreendia que, mesmo a clínica a dois, é uma ação política. Ela trazia na sua bagagem - construída pelos caminhos percorridos na travessia da fronteira de várias cidades, países e de três continentes que habitou - a experiência da arte. E com ela, a compreensão de que o corpo tem lugar de muita importância na revolução pessoal que começa sempre a dois. Começa na fronteira onde e quando encontro o outro diferente. No arrepio da pele sempre que a novidade me surpreende, me espanta. A pele, nossa fronteira de contato, tem menos uma função de nos separar e mais de contornar e conter a parte mais dentro do corpo. A pele é local de encontro. Quando ela arrepia, sinaliza que há vida, dá os primeiros sinais de um movimento iminente que nos deslocará para outro lugar, no exercício gestual que cria outras formas de ser, de estar, de compreender o mundo e o outro, de transformar o outro e nós, pelo menos levemente. Este processo, que a Gestalt-Terapia denomina ajustamento criativo, pode afrouxar as amarras que nos prendem em portos que parecem tão seguros, mas que não nos permitem navegar. Para acontecer, ele exige o arrepio da pele e a coragem de levantar âncoras, abrindo-nos para o que ainda não sabemos, não conhecemos, não somos.

Com o intuito de provocar esta reflexão, pergunto-nos sobre as amarras que temos como terapeutas, e as amarras que tem a Gestalt-Terapia como clínica. Cabe perguntarmo-nos também sobre que abertura temos para a diferença, que compromisso temos com os nômades das borderlands, os invisibilizados, os que vivem nas margens.

É necessário e urgente interrogarmo-nos sobre que clínica fazemos. E para quem a fazemos.

Há uma grande tensão social e política que vem afetando nossas vidas nesses tempos de polarizações, de vidas ensimesmadas, onde 0 
outro e a diferença são ameaças a serem controladas e aniquiladas. Tempos de medo e de insegurança. Tempos de an-estesiamentos, perda da capacidade de sentir e arrepiar a pele, em que o corpo, ao invés de guiar, é moldado segundo padrões externos. Tempos em que a imagem clichê é soberana, dirigindo os olhares e guiando os sujeitos por trilhos de sentidos sedimentados, invisibilizados e inconscientes que impregnam nossos modos de ver e sentir.

Diante dessa situação, não nos é recomendado tapar os olhos para evitar ver o que nos inquietaria ao olharmos, mas, ao contrário disso, lançarmo-nos na aventura do encontro na fronteira, apostando na premissa gestáltica do encontro com a diferença que é o melhor modo de combater a polarização e a invisibilização.

Como clínicos e pesquisadores, é fundamental enxergarmos essas linhas de forças invisíveis que, como afirma Merleau-Ponty (2000), não são um inconsciente atrás de nós, mas estão nas articulações do campo, da situação. De acordo com o filósofo, o visível é sustentado e entretecido com uma dimensão invisível, e "É próprio do visível ser a superfície de uma profundidade inesgotável." (Merleau-Ponty, 2000, p. 139). Ainda segundo Merleau-Ponty (2000), a noção de profundidade tal como ele coloca, não implica pensar em uma profundidade como interioridade subjetiva, mas uma dimensão oculta e simultânea dada na coexistência dos sujeitos como linhas de forças, dimensões, formando uma "armadura interior" (p. 144) do mundo invisível. E essa armadura que, com a fala, "começa a impregnar todas as coisas que vemos." (p. 174).

Nesse sentido é que propomos discutir um tipo de invisibilidade de determinadas dimensões que resulta de um processo histórico de objetivaçãa. Tal invisibilidade reflete um tipo de visão desencarnada, analítica e que pretende sobrevoar os fenômenos, produzida por modos de fazer ciência que se mantiveram dominantes. Estes modelos científicos foram produzidos em determinado contexto sóciohistórico e ideológico, e não podem ser separados de uma análise que considere a ideologia e as estruturas de poder. Tais estruturas produzem forças que visam poder e dominação, agindo de formas diversas para a manutenção de certa ordem em detrimento de outras. A título de exemplo, cito a discussão de Federici (2017), que propõe uma crítica do pensamento marxista feita a partir de um olhar sobre a história de um ponto de vista feminino. Para ela, esse olhar "Implica uma redefinição fundamental das categorias históricas aceitas e uma visibilização das estruturas ocultas de dominação e exploração." (Federici, 2017, p. 29). Federici cita o trabalho de Carolyn Merchant e de Maria Mies que deslocam o ponto de vista que tradicionalmente orienta as pesquisas, respectivamente assumindo 0 ponto de vista feminino e não-eurocêntrico.

Antes de tudo, considero fundamental pensar no trabalho clínico da Gestalt-Terapia como um trabalho com a experiência de contato que, 
a partir da relação atual, visa a alcançar a possibilidade plástica de transformar e ultrapassar formas fixadas de existir. Tais formas fixadas que compõem experiências singulares são, entretanto, produzidas no campo ou na situação social mais ampla. Como propõem Perls, Hefferline e Goodman (1997) a Gestalt-Terapia é uma abordagem integrativa que deve levar em consideração todo problema como se dando num campo social-animal-físico. "Não se podem considerar fatores históricos e culturais modificando ou complicando condições de uma situação biofísica mais simples, mas como intrínsecos à maneira pela qual todo problema se nos apresenta." (Perls, Hefferline, \& Goodman, 1997, p. 43). Assim, nosso cuidado que se dá na relação pessoal, no nível micro, a dois ou em grupo, não prescinde de uma ação no nível macro, no campo social mais amplo. Onde precisamos atuar mais e fazer um trabalho que dê a ver o invisível que afeta e sustenta o visível. Temos notícias da existência de muitas práticas gestálticas nessas fronteiras centromargem, no trabalho com pessoas invisibilizadas ou vítimas contumazes de tentativas de invisibilização como a população LGBTQI (Lésbicas, Gays, Bissexuais, Transexuais, Queer e Intersexo), a população negra, as mulheres, os favelados, e consideramos necessário no atual contexto que essas práticas se proliferem, atualizando a potência política da Gestalt-Terapia.

Vejo na essência do trabalho da Gestalt-Terapia, uma clínica que busca promover o reconhecimento de si pelo reconhecimento mútuo, nessa relação pautada por uma ética da alteridade, inseparável de uma ética da transformação. Tendo como um de seus fundamentos a perspectiva fenomenológica e de campo, a Gestalt-Terapia se distancia de um pensamento de sobrevoo e considera que o trabalho com os processos de produção de subjetividade ou "selfing" acontece na relação horizontal estabelecida entre terapeuta e cliente. Deste modo, não devem estar sujeitos a pontos de vista especializados ou técnicos, que falem por eles. Em nossas experiências extensionistas, que discutiremos brevemente a seguir, buscamos a alteridade e 0 reconhecimento como forma de resgatar a capacidade de agência, a partir de uma ação clínica gestáltica ampliada para a situação-favela que convoque no coletivo a fala falante e instituinte dos próprios sujeitos e que não fale por eles, caindo em um outro modo de representação, tal como discute Spivak (2010).

\section{Uma proposta de clínica gestáltica na fronteira com crianças e jovens de favelas}

Nas minhas experiências de gestalt-terapeuta vivendo nas fronteiras, tenho junto com estudantes encontrado com crianças e jovens em favelas do Rio de Janeiro para construir com eles, em torno de 
fazeres artísticos e lúdicos, uma compreensão da situaçãoadolescente e situação-infância vivida naqueles territórios. Buscando com este trabalho compreender melhor e ressignificar nossa situação-psicólogo-cidadão do Rio de Janeiro, junto com essas pessoas em formação.

O projeto "Expressão e Transformação: arte e subjetivação com crianças e jovens", realizado na Mangueira entre 2010 e 2017, e o projeto "Adole-Ser em Movimento", realizado atualmente no Complexo do Alemão e em uma escola em Ricardo de Albuquerque, são dois projetos de pesquisa e extensão que têm como base a Gestalt-Terapia e a fenomenologia. Consistindo em modelos de pesquisa-ação, têm como questão de pesquisa: "como é ser adolescente nesta comunidade?" e propõem aos jovens interessados em participar, um trabalho de pesquisa coletiva que envolve todos na tarefa de pesquisar a situação adolescente naquele tempo e lugar. Com grupos que variam entre 10 e 16 adolescentes entre 14 e 17 anos, promovemos encontros semanais em espaços da comunidade proporcionados por parcerias estabelecidas com organizações nãogovernamentais e escolas municipais, em torno do projeto previamente aprovado no Comitê de Ética em Pesquisa do Centro de Filosofia e Ciencias Humanas da Universidade Federal do Rio de Janeiro (UFRJ) e com o consentimento formal dos participantes e responsáveis nos respectivos registros de assentimento e consentimento livre e esclarecido.

Trabalhando a partir das dimensões existenciais corpo, espaçotempo, alteridade e diálogo, e nossas propostas de experiências lúdicas e artísticas feitas com as crianças e os com jovens, os convidam a implicar o corpo na relação com o mundo e com o outro para perceber o modo como vivenciam o espaço, o tempo e as relações. Pretendemos, em última instância, criar formas de reconhecimento que os permita sair do lugar de Outro sempre submetido e objetificado pelo olhar estrangeiro, e plantar no solo de suas existências pelo menos uma semente da experiência de ser-Um, do direito ao lugar de pessoa-Um, modo como denominaremos doravante os que têm direito à sua diferença, sendo o ponto de referência para que outrem seja visto como outro.

Tal como compreendo a partir da obra de Merleau-Ponty, é a condição de ser (como) corpo que me dá a possibilidade de encontrar o outro - que também é (como) corpo - e considerá-lo um igual. Que, entretanto, não é idêntico e pode me surpreender com sua diferença. $O$ racionalismo da modernidade europeia que encobriu o outro, como discutimos, também tentou apagar o corpo, transformando os sujeitos em homens-máquina, outra forma de dominação e tentativa de impedir o movimento de travessia de fronteiras. Tal como discuti anteriormente (Alvim, 2012, 2014) a fenomenologia, a Gestalt-Terapia e a arte moderna são reações a 
isto, são propostas que resgatam o corpo e a experiência, e é a partir delas que enfatizo o trabalho com a experiência, o corpo e a arte.

Penso no cuidado na clínica gestáltica como um tipo de acolhimento e escuta que permite reconhecimento de si, e reconhecimento mútuo na expressão e no compartilhamento do sentir, que permite 0 diálogo. Compartilhar o sentir resulta do desafio de encontrar o que nossa vida tem de comum, de articulado, a partir do mundo que se apresenta. Bonomi (2004), ao discutir o conceito de normalidade a partir da fenomenologia, levanta algumas questões acerca da diversidade da experiência do outro, tocando no problema do reconhecimento. Ele apresenta dois questionamentos simétricos que se constituem em pistas metodológicas para nosso trabalho. 0 primeiro deles pergunta como é possível abordar outra subjetividade ou outra cultura sem reduzi-las preliminarmente às nossas coordenadas. O segundo, simétrico ao primeiro, pergunta se "O fato de preservar em sua peculiaridade a experiência para a qual me volto, não a transforma em algo insignificante para mim, já que corro o risco de privá-la daquilo que a torna comum à minha experiência." (Bonomi, 2004, p. 80). Ele descreve a partir daí um duplo movimento, que implica por um lado, em reconhecer a experiência do outro em sua especificidade, sem considerá-la uma manifestação falhada da nossa. Por outro, em explicitar o quanto há de comum entre elas, já que como sujeito situado em um dado universo cultural só desse modo isso seria possível. Ele conclui: "A consideração de uma experiência diferente da nossa é significante para nós apenas na medida em que nos implica, em que coloca em causa a nossa própria experiência: há então reciprocidade entre o observador e o observado." (Bonomi, 2004, p. 81).

As crianças e os jovens que encontramos no complexo do Alemão, crescidas ali naquelas zonas de fronteira, vivem a experiência radical da guerra do tráfico. Da violência cotidiana, das invasões de suas casas e ruas, dos helicópteros que atiram do alto. Do não reconhecimento de sua condição de humanos de direitos.

A maior parte das referências identitárias que aparecem em seus sonhos de futuro são pessoas-Um que, paradoxalmente, as mantêm excluídas dos direitos de serem também uma pessoa-Um. Eles sonham ser militares, policiais.

Seus horizontes espaciais invariavelmente aparecem deslocados do espaço onde vivem nas periferias em direção ao centro: nos sonhos de saírem da favela, serem ricos, morarem na Zona Sul, em Nova Iorque, em Dubai. Ou subirem na vida de um modo "mais realista" e individualista - estudando e competindo por um lugar. Os mais engajados se frustram, como dito na frase que ouvimos semanas atrás: "A gente tenta sair da favela, mas eles empurram a gente de volta pra cá." Esta frase foi dita por Esperança Maria, contando o acontecido com um amigo que ia para o curso de inglês depois de ter 
conseguido uma bolsa com muito esforço. Foi parado no caminho pela polícia, tendo sido detalhadamente revistado e longamente interrogado, acabando por perder a prova. O fato é que sonhando de forma mais realista ou irrealista, rejeitam se ver e falar de si como moradores da favela. Trazem introjetadas concepções de que ser favelado é ser errado, falhado, marginal.

Do outro lado da fronteira estamos nós, terapeutas, estudantes, habitantes do centro onde se situa a universidade, os intelectuais, os que querem se tornar intelectuais, a classe média letrada. Chegando na borderland e propondo-nos à experiência da fronteira como um encontro, se abrirmos bem os poros e os olhos, ficaremos fascinados com algumas coisas que existem lá e que não vemos mais por aqui. Nesses espaços de diversidade, de mestiçagem, há um fervo de vida no espaço público: nos pés descalços das crianças que brincam na rua, correm e gritam, livres, paradoxalmente livres; nas pessoas que se sentam nas portas, que da porta de suas casas gritam o vizinho cuja porta está mais acima da curva que faz a viela e que não pode ser vista dali; ou se comunicam pelo alto das lajes; nas vendas, nos botecos, nos caminhos que levam e trazem para o trabalho, para a escola, onde há poucos carros e muita gente que circula, se encontra, se ajuda, se socorre, discute, briga, faz as pazes, fala mal, faz fofoca, gente que vive na fronteira, de portas abertas e que não sabe o que é viver entre paredes de tijolos que isolam.

Nas borderlands as pessoas dançam. Ouvem música alta. Os corpos são ágeis e guardam nos seus movimentos a ancestralidade africana e indígena, conectados com a terra que eles objetivamente nem têm, com a experiência coletiva, com o ritmo dos sons que rege esse movimento.

No encontro com eles, na fronteira de contato, somos provocados por arrepios diversos: de espanto e encantamento com a alegria que insiste, apesar de tudo; de indignação e raiva com o sofrimento que transborda em seres tão jovens que quando sofrem o impacto da realidade, se cortam, se deprimem, se depreciam e cada vez em maior número desejam morrer. Uma jovem na Mangueira uma vez nos disse: "Sonhos? Que sonhos, tia?Aqui a gente começa a sonhar e leva logo três tapas na cara." E nesse momento, nesse breve diálogo que nos atinge como um tapa na nossa própria cara, nos encontramos com eles em um lugar que não há palavras para dizer. O que dizer a esta adolescente sobre sonhar, sabendo que o Estado não está presente, que o direito não é para todos e que o futuro não aponta perspectivas? Mas nesse lugar que não pode ser dito podemos ainda permanecer, sentindo juntos, reconhecendo a legitimidade da dor, ajudando a dar a ela um contorno que ultrapasse o sujeito para incluir o social na origem do sofrimento.

Em nosso cuidado de terapeutas, temos no eixo do reconhecimento um princípio central que está na base de nossos gestos. 0 
reconhecimento da legitimidade da dor. Da ausência de direitos básicos. Da precariedade da vida. Da injustiça social. O reconhecimento da nossa diferença que nos ensina, com a navalha na carne, sobre o nosso lugar privilegiado, no centro. O reconhecimento da diferença deles, do seu direito de ser aqui comigo do seu jeito, no seu lugar de falar, no seu direito inalienável de narrar a si mesmo.

E o reconhecimento da legitimidade da alegria que às vezes fura, sorrateira, as camadas duras daquele solo e explode nos corpos, faz eles sonharem e se movimentarem, sentindo sua potência de agir e nos encantando com seu fervo de vida. Nesse reconhecimento também está uma dimensão terapêutica importante. Seu desejo de sair da favela e as ideias introjetadas de que ser favelado é ser errado, sem valor, uma manifestação falhada em relação aos habitantes do centro, nos mostra que eles próprios não reconhecem sua experiência em sua especificidade, o que implica numa experiência de utopia, uma vida em uma espécie não-lugar. Se nosso reconhecimento mudo de suas experiências de dor podem contribuir para que elas adquiram um contorno e uma concretude, nosso reconhecimento da sua alegria na dança, no funk, da sua vida como é vivida no fervo da favela, nas vielas, no samba, da sua força de resistência na capacidade de reinventar a vida num contexto tão desfavorável, permite talvez um deslocamento no seu olhar sobre seu próprio lugar. Em itinerâncias pela favela, eles são convidados a criarem outro tipo de percurso e relação com os espaços que os desloquem de formas naturalizadas de ver e perceber o lugar. Por vezes, com convites para fotografar seu caminho, seu cotidiano em casa, na escola. Por vezes nos conduzindo a lugares que eles gostariam de nos mostrar.

Em nossa prática, vivemos diversas experiências de deslocamento, em vários sentidos. Com nosso movimento rumo à fronteiraborderland, rompemos com o modelo hegemônico de práticas clínicas fazendo deslocamentos do centro para as margens, do consultório para o lugar onde vivem as pessoas; de um psiquismo interiorizado para um corpo em movimento engajado na situação; da neutralidade para a implicação do clínico-pesquisador, da disciplina para a interdisciplina. Propondo experimentações artísticas, trabalhamos com eles deslocamentos imaginários por lugares, tempos, encontros com outros. Trabalhamos também com deslocamentos concretos, em itinerâncias por outros espaços da cidade. Nas performances, teatro, dança e itinerâncias, as crianças e jovens - e nós também - nos deslocamos geográfica e subjetivamente, ao mesmo tempo.

Nesses deslocamentos, vivemos, inexoravelmente, experiências de descentramento (Merleau-Ponty, 2000), que em termos gestálticos correspondem à experiência de fronteira. Essa experiência, que como proposto no contexto da arte moderna, permite descentrar o olho e 
desnaturalizar a percepção, dando a ver (e a sentir) o que afeta sem se mostrar.

E vivendo na fronteira com os corpos acordados por tantos arrepios, somos instados a movimentos de criação que possam recobrar - ou conquistar - lugares outros. Lugares no micromundo e no macro mundo social. Lugares de humanos direitos. E mesmo que eles ainda não tenham lugar, sejam ainda u-tópicos, insistimos e seguimos acreditando.

\section{Considerações Finais}

A proposta que discuto aqui, de fazer uma clínica na fronteira e nessa experiência de alteridade colocar no centro a busca do reconhecimento de si pelo reconhecimento mútuo, visa a promover um trabalho que permita dar a ver o que afeta sem se mostrar, trazendo para o visível as forças invisíveis que operam estruturalmente e que se concretizam em entraves para o desenvolvimento pessoal. Essa proposta exige deslocamentos que discuti e que deixo aqui como um convite-provocação a nós, gestaltterapeutas.

Nossas experiências extensionistas com crianças e jovens de favelas, nos colocaram em contato com espaços-tempos demarcados por fronteiras invisíveis que separam e categorizam pessoas, objetivando-as e mantendo sua invisibilidade. O lugar reservado para nós, psicólogos e pesquisadores, é um lugar de saber científico, que se não for ocupado com zelo, pode se transformar no lugar de quem ve objetivando e invisibilizando. A tentativa de assumir o ponto de vista da criança pobre e favelada, em sua maioria preta, ou da mulher que conduzia essa criança até nós para participar do projeto, foi uma experiência que nos pareceu a princípio uma tarefa impossível, mas que seguindo os caminhos de uma escuta clínica pautada pela ética da alteridade vem se anunciando timidamente em nossa prática, quase como uma promessa de futuro.

Buscar uma visão enraizada no corpo e no movimento, sabendo de antemão que "ver não é apoderar-se, mas aproximar-se; não é possuir mas abrir para" (Barbaras, 2005, p. 70) permitiu nos aproximar da profundidade e da não-visibilidade que suscita um movimento de exploração. De forma que - correndo os riscos de parecer paradoxal nessa argumentação - a aproximação da nãovisibilidade vem nos permitindo vislumbrar, com eles, na base de suas existências, estruturas de dominação e opressão que agem fortemente na produção e reprodução de subjetividades e de sofrimentos. Essa exploração, corporal, artística, expressiva, é nossa aposta para um tipo de visibilização que seja, simultaneamente, provocada por e provocadora de gestos criativos e inventivos, na 
esperança de reinvenção da vida. Na emergência de falas instituintes de vozes que saiam do silêncio, de corpos que saiam da invisibilidade e assumam protagonismos no cenário social.

Nesse percurso aqui compartilhado, entre encantamento e indignação, esperança e desesperança, vida e morte, reafirmamos nossa escolha por uma clínica na fronteira. Escolhemos o arrepio da pele. O aperto do coração. E mantemos sempre no nosso horizonte uma pergunta: o que importa ao outro que Ihe façamos?

\section{Referências}

Alvim, M, B. (2012). A clínica como poiética. Estudos e Pesquisas em Psicologia, 12(3), 1007-1023. doi: 10.12957/epp.2012.8234

Alvim, M. B. (2014). A poética da experiência: Gestalt-terapia, fenomenologia e arte. Rio de Janeiro, RJ: Garamond.

Alvim, M. B., \& Castro, F. G. (Eds.). (2015). Clínica de situações contemporâneas: Fenomenologia e interdisciplinaridade. Curitiba, PR: Juruá.

Anzaldúa, G. (1999). Borderlands: the new mestiza = La frontera. San Francisco, EUA: Aunt Lute Books.

Barbaras, R. (2005). O invisível da visão. In A. Novaes (Ed.), Muito além do espetáculo (pp. 64-78). São Paulo: Editora Senac.

Bonomi, A. (2004). Fenomenologia e estruturalismo. São Paulo, SP: Perspectiva.

Didi-Huberman, G. (2010). O que vemos, o que nos olha. São Paulo, SP: Editora 34.

Dussel, E. (1993). 1492: o encobrimento do outro. A origem do mito da modernidade. Petrópolis, RJ: Editora Vozes.

Federici, S. (2017). Calibã e a Bruxa: mulheres, corpo e acumulação primitiva. São Paulo, SP: Editora Elefante.

Merleau-Ponty, M. (2000). O visível e o invisível. São Paulo, SP: Perspectiva.

Paulinho da Viola. (1993). Timoneiro. Paulinho da Viola (Ao Vivo). Brasil: BMG Music.

Perls, L. (2012). Living at the Boundary. Gouldsboro: The Gestalt Journal Press.

Perls, F., Hefferline, R., \& Goodman, P. (1997). Gestalt-Terapia. São Paulo, SP: Summus.

Ricoeur, P. (2006). Percurso do reconhecimento. São Paulo, SP: Edições Loyola.

Santos, B. S. (1994). Pela mão de Alice: O Social e o Político na PósModernidade. Porto, Portugal: Edições Afrontamento.

Spivak, G. C. (2010). Pode o subalterno falar? Belo Horizonte, MG: Editora UFMG. 


\section{Endereço para correspondência}

\section{Monica Botelho Alvim}

Universidade Federal do Rio de Janeiro - UFRJ

Instituto de Psicologia - Programa de Pós graduação em Psicologia

Av Pasteur, 250, Praia Vermelha, CEP 22290-240, Rio de Janeiro - RJ, Brasil

Endereço eletrônico: mbalvim@gmail.com

Recebido em: 13/10/2019

Reformulado em: 26/12/2019

Aceito em: 04/01/2020

\section{Notas}

* Psicóloga, mestrado e doutorado pela Universidade de Brasília, pós-doutorado pela Universidade Paris 1 Panthéon-Sorbonne, professora da UFRJ.

Este artigo de revista Estudos e Pesquisas em Psicologia é licenciado sob uma Licença Creative Commons Atribuição-Não Comercial 3.0 Não Adaptada. 